\title{
'Ā'ISHA BINT ABĪ BAKR: MUJER, GUERRA Y PODER EN LA ARABIA PALEO-ISLÁMICA ANTES DE LA PRIMERA FITNA
}

\author{
'A' ISHA BINT ABĪ BAKR: WOMAN, WAR AND POWER \\ IN PALEO-ISLAMIC ARABIA BEFORE THE FIRST FITNA
}

Carlos Martínez Carrasco

Universidad de Granada

\section{RESUMEN}

Este estudio se orienta hacia la parte menos conocida de la vida de 'A' isha bint Abī Bakr, la de los años previos a la guerra civil. Me centro en su relación con lo militar en el contexto de las guerras que dieron paso al nacimiento del islam como entidad política. Y lo hago tomando como eje tres momentos en los que ella aparece como protagonista directa o indirecta, y en este último caso saltando las barreras sociales. Una 'A' isha más cercana a una "señora de la guerra" que a una matrona musulmana.

Palabras clave: Edad Media, Paleo-islam, Arabia, Califato, 'A' isha

\section{ABSTRACT}

This study deals with the lesser known part of the life of ' $\bar{A}$ ' isha bint Abī Bakr, namely the years prior to the civil war. I focus on her relationship with the military in the context of the wars which led to the birth of Islam as a political entity. The study revolves around three moments in which she appears as a direct or indirect protagonist, and in this last case overcoming social barriers. An ' $\overline{\mathrm{A}}$ ' $\mathrm{i}$ sha closer to a "lady of war" than a Muslim matron.

Keywords: Middle Age, Paleo-islam, Arabia, Caliphate, 'A' isha 


\section{RESUM}

\section{A' ISHA BINT ABĪ BAKR: DONA, GUERRA I PODER A L' ARÀBIA PALEO-ISLÀMICA ABANS DE LA PRIMERA FITNA}

Aquest estudi s'orienta cap a la part menys coneguda de la vida ' $\bar{A}$ 'isha bint $A b i ̄$ Bakr, als anys previs a la guerra civil. Em centre a la seua relació amb l'àmbit militar al context de les guerres que van donar pas a l'islam com a entitat política. I ho faig prenent com a eix tres moments en els quals ella apareix com a protagonista directa $o$ indirecta, $i$ en aquest darrer cas saltant les barreres socials. Una 'A' isha més propera a una "dona de la guerra" que a una matrona musulmana.

Paraules clau: Edat Mitjana, Paleo-islam, Aràbia, Califat, 'A' isha. 
' $\bar{A}$ 'isha bint Abī Bakr es una figura fundamental en el islam por su papel como transmisora de la tradición religiosa: muchos hadîthes la citan como fuente de autoridad.' Pero se trata de un personaje con aristas y claroscuros, denostada por su actuación política, que describen con el término árabe bid'a (=innovación), un sinónimo de herejía en el mundo islámico. ${ }^{2}$ Como esposa de Muhammad fue testigo de excepción de las guerras que éste sostuvo contra los qurayšíes por hacerse con el control de La Meca. Más tarde, como su viuda, ella misma se convirtió en parte activa en la primera fitna que sacudió el califato entre 656-661, terminando así con la edad de oro mítica del islam primitivo.

1 BARLAS, Asma (2002), "Believing women" in Islam. Unreading Patriarchal Intrepretations of the Qur'ān, University of Texas Press, Austin, p. 46; SHAIKH, Sa'diyya (2004), "Knowledge, Women and Gender in Hadith: a Feminist Interpretation", Islam and Christian-Muslim Relations, vol. 15:1, pp. 99-108, espec. 100; y GEISSINGER, Aisha (2011), "'A'isha bint Abi Bakr and Her Contributions to the Formation of the Islamic Tradition", Religion Compass, vol. 5:1, pp. 37-49, espec. 40.

2 MERNISSI, Fátima (1999), El harén político. El Profeta y mujeres, Ediciones del Oriente y del Mediterráneo, Madrid, p. 16; PETERS, Francis E. (2007), Los hijos de Abraham. Judaísmo, Cristianismo, Islam, Laertes, Barcelona, p. 69; y EL CHEIKH, Nadia Maria (2015), Women, Islam, and Abbasid Identity, Harvard University Press, Cambridge, Massachusetts/Londres, p. 106. 
La mayoría de los estudios que, como los de Denise A. Spellberg, han abordado la dimensión política y militar de 'A' isha lo hacen tomando como eje la batalla del Camello o de Basora (656), por la rareza que representa el hecho de que una mujer se pusiera al frente de un ejército, si bien la historia de los árabes ofrece ejemplos de reinas guerreras como Mavia en el siglo IV d.C. ${ }^{3}$ No obstante, en este estudio me propongo abordar su relación con la guerra antes de ese acontecimiento; su implicación en las campañas dirigidas por Muhammad, pero también en las posteriores conquistas, donde trataré de dibujar la línea que le llevó de ser un elemento pasivo a participar de manera activa en la vida política y militar del primer islam. En esta evolución intentaré determinar el impacto que tuvo la falsa acusación de adulterio que lanzaron contra ella y que revistió un aspecto determinante de las guerras tribales en la Arabia pre-islámica: la propaganda a través de la poesía.

Lamentablemente, no tenemos ningún documento escrito por la propia ' $\overline{\mathrm{A}}$ ' $\mathrm{i}$ sha en el que ella exprese su visión, por lo que nos vemos obligados a (re) construirla a través de interpretaciones masculinas que en ocasiones han tergiversado su figura con el fin de adaptarla a las necesidades del discurso dominante vigente cuando se compusieron. En este estudio, parto de las fuentes islámicas más tempranas escritas entre mediados del siglo VIII y la primera mitad del $X$, cuando se está poniendo por escrito la memoria de lo sucedido durante el período pre-islámico y paleo-islámico; una memoria construida en virtud de las necesidades de legitimación de la dinastía 'Abbāsí. Hay que tener en cuenta este aspecto para abordar de manera crítica la imagen, no siempre positiva, de una mujer que puso en entredicho la hegemonía masculina en el campo político-militar.

\section{Testigo de la guerRa: espacio privado-femenino VS. Espacio público-mas- CULINO}

El primer contacto de ' $\overline{\mathrm{A}}$ 'isha con la guerra y lo militar del que tenemos noticia es la batalla de al-Khandaq (=el Foso), en el año $5 \mathrm{AH}$ (ca. 627), de la que fue testigo. Ella, junto al resto de mujeres de los musulmanes y sus hijos, fue enviada a los fuertes de Medina en el momento en el que aparecieron los judíos medineses y sus aliados mecanos. ${ }^{4}$ Era una batalla

3 SOTO CHICA, José (2019), "Señoras de la guerra en la Alta Edad Media: el caso de la reina Mavia", en SANTIRSO, Manuel y GUERRERO, Alberto (coords.), Mujeres en la guerra y los ejércitos, Libros de la Catarata, Madrid, pp. 79-90.

4 Ibn Isḥāq, Sïrāt, p. 453 [GUILLAUME, Alfred $\left(2004^{17}\right)$, The Life of Muhammad. A translation of Ibn Isḥāq's Sīrāt Rasūl Allāh, Cambridge University Press, Oxford/Nueva York]. 
desigual, si atendemos a las cifras que dan los tradicionistas musulmanes: diez mil aliados contra tres mil musulmanes. ${ }^{5}$ Se trató un sitio en toda regla, si nos atenemos a la descripción que ofrece lbn Isḥāq, lo cual casa mal con la imagen de los guerreros árabes pre-islámicos y aquéllos que protagonizaron la conquista, descritos como un grupo indisciplinado, carente de formación militar y mal armado: "El Apóstol [i.e. Muhammad] y los politeístas permanecieron más de veinte días, cerca de un mes, sin luchar, excepto por algunos disparos de arco y el sitio". 6 El ejército enemigo había sido detenido por los fosos que mandó construir un Muhammad que el año anterior, $4 \mathrm{AH}$ (ca. 625-626), fue derrotado en la batalla de Uhud y necesitaba un golpe de efecto que le devolviera a los musulmanes la confianza en él y su mensaje.

Como reconocerían sus enemigos, esta táctica era algo nuevo entre los árabes, habituados a los choques frontales entre los grupos tribales. ${ }^{7} \mathrm{Se}$ trataba de una innovación que respondía a otros usos de la guerra que al parecer eran ajenos a la península arábiga. Todos señalan que la idea de cavar trincheras fue idea de Salmān al-Fārisi (=el Persa) con la que la comunidad entera estuvo de acuerdo. Incluso el propio Muhammad trabajó en las trincheras como uno más. ${ }^{8}$

Desde el fortín de los Banū Ḥāritha, el mejor protegido de Medina, ${ }^{9}$ 'A' isha tal vez fuera testigo del combate singular que mantuvieron 'Alī ibn $A b \bar{i}$ Țālib, primo y yerno de Muhammad, y 'Amr ibn 'Abdu Wudd, paladín de los mecanos. Desde allí también podía ver cómo Khālid ibn al-Walīd y 'Amr ibn al-'Ās comandaban la caballería de los politeístas y causaban numerosas bajas a los musulmanes. Curiosamente, es un tradicionista como Ibn Sa'd quien convierte a estos dos emires en personajes principales del episodio de al-Khandaq, ${ }^{10}$ sobre todo teniendo en cuenta el papel que tendrían a posteriori como los principales artífices de las conquistas de las provincias romanas y persas y la consolidación del califato.

5 Ibn Sa'd, Tabaqāt, ii. 1, p. 81 [MOINUL Haq, S. (1990), Ibn Sa'd's Kitab al-Tabaqat al-Kabir, vol. II, parts I \& II, Kitab Bhavan, Nueva Delhi].

6 Ibn Isḥāq, Sīrāt, p. 454.

7 Ṭabarī, Ta'rīkh, viii, p. 18 [FISHBEIN, Michael (1997), The History of al-Tabarī. Vol. 8: The Victory of Islam, SUNY, Nueva York]; Ibn Isḥāq, Sïrāt, p. 454.

8 Ibn Sa'd, Tabaqāt, ii. 1, p. 81.

9 Ibn Isḥāq, Sīrāt, p. 457.

10 Ibn Sa'd, Țabaqāt, ii. 1, pp. 84-85. 
El duelo entre 'Alī y 'Amr reviste detalles que recuerdan a la llíada de Homero. Sin embargo, sería éste una variante árabe del mard-o-mard, el combate entre dos hombres iguales, propio de la cultura caballeresca persa sasánida. ${ }^{11}$ Los árabes no fueron ajenos a los usos militares de los dos grandes Imperios, el romano y el persa. De este modo, de 'Amr se dice que "llegó portando signos distintivos de su rango", 12 lo que indicaría una jerarquía que iba más allá de lo tribal y avanza la posibilidad de una organización militar. Al ser una fuente escrita poco después de la Revolución 'Abbāsí, con Ibn Isḥāq quizás no sirvan las precauciones de las que hablaba $\mathrm{H}$. Kennedy para negar que existiera alguna estructura en los primeros ejércitos islámicos, achacándolo todo a un anacronismo de los tradicionistas, que proyectaban la realidad de su época al pasado idealizado. ${ }^{13}$

Igualmente importante es la mención a cómo se presentó 'Alī. Según la descripción que ofrece Ibn Isḥāq: "se levantó vestido con la armadura y le pidió permiso al Profeta para luchar contra él ['Amr]" ${ }^{14}$ Teniendo en cuenta que este mismo autor menciona de manera particular las cotas de malla, es posible que lo que vistiera fuera una de esas armaduras laminadas, al estilo romano-persa. Después de todo, 'Alī pertenecía a la aristocracia mecana y serían hombres como él, con cierta riqueza, los que podían costear la adquisición y el mantenimiento de este equipo. Se podría pensar que estos artículos llegaron al Hidjāz a través del comercio o fruto del pillaje en el limes romano o persa. No obstante, hay que suponer la existencia de armeros locales. El que sería el segundo califa del islam, 'Umar ibn alKhatțāb (634-644), señala cómo la armadura de lbn 'Abdu Wudd era "la mejor que podía encontrarse entre los árabes". ${ }^{15}$ No obstante, la tradición que transmite lbn Sa'd se presenta mucho más islamizada, más acorde con lo que se suponía debía ser el "espíritu del islam primitivo", describiendo cómo Muhammad dio su espada a "Alī y lo encomendó a Dios para que le diera la victoria sobre un 'Amr de noventa años. ${ }^{16}$ ¿ Una metáfora de la lucha entre lo nuevo - el islam - y lo viejo - el politeísmo-?

11 CHRISTENSEN, Arthur (1944), L'Iran sous les Sassanides, Ejnar Munksgaard, Copenhague, p. 216; y FARROKH, Kaveh (2007), Shadows in the Desert. Ancient Persia at War, Osprey Publishing, Oxford/Nueva York, pp. 180-181.

12 Ibn Isḥāq, Sïrāt, p. 455.

13 KENNEDY, Hugh (2001), The Armies of the Caliphs: Military and Society in the Early Islamic State Warfare and History, Routledge, Londres/Nueva York, p. 3.

14 Ibn Isḥāq, Sïrāt, p. 455.

15 Ibn Isḥāq, Sīrāt, p. 456.

16 Ibn Sa'd, Tabaqāt, ii. 1, p. 83. 
'Amr descendiendo del caballo que montaba a petición de 'Alī, para poder luchar ambos a la misma altura. El paladín musulmán parando el golpe de espada que le lanza su rival. El arma que queda embotada en el escudo del rival. El contraataque de 'Alī que derriba a su oponente de un golpe en el cuello. El cuerpo sin vida de 'Amr que cae levantando una enorme polvareda. En otras versiones, es el polvo que se levanta, providencial, lo que ayuda en su victoria al campeón musulmán. ${ }^{17}$ El grito de "Allah Akbar" que profiere Muhammad cuando ve que el resultado del duelo es el esperado y su primo y yerno sigue con vida. La reconvención que le hace 'Umar a 'Alī por no haber despojado a 'Amr de sus armas. La respuesta que le da, justificándose en que eso no era digno. ${ }^{18}$ Es una escena que bien podía haber salido de la llíada homérica o de la Eneida de Virgilio, pero que entronca con los ideales caballerescos de los que hacen gala los poetas-guerreros árabes de las mu allaqāt, la poesía pre-islámica, compuestas en su mayoría en el entorno cortesano de al-Ḥīra, la capital de los Banū Lakhm, aliados de la Persia sasánida. ${ }^{19} Y$ curiosamente, es Ibn Ishāa quien se recrea en todos estos detalles, dejando entrever que el público potencial de su obra estaba familiarizado con estos valores militares. Se contrapone a la parquedad que observamos en el relato de al-Ṭabarī, mucho más seco y carente de épica, ${ }^{20}$ quizás porque el tiempo de los 'Abbāsíes estaba marcado por otro tipo de códigos.

Uno de esos cambios tuvo que ver con el hidjāb, la cortina que debía separar a las mujeres de los varones. El momento en que pasó a ser obligatorio, marcó la separación entre hombres y mujeres dentro de la Umma, la comunidad islámica. ${ }^{21}$ Pero su uso aún no estaba vigente cuando tuvo lugar la batalla del Foso y así lo dice la propia ' $\bar{A}$ ' isha cuando relata la entrada en el torreón de los Banū Ḥāritha de Sa'd ibn Mu'āth, cuya madre era una de las musulmanas que se refugiaron con la joven esposa del Profeta. ${ }^{22} \mathrm{De}$ acuerdo con la tradición que se le atribuye a ella misma, Sa d entró en las estancias donde estaban las mujeres para armarse con una cota de malla, pero ésta era demasiado corta para cubrirle por completo el cuerpo; herido por una flecha que le seccionó la vena mediana del brazo, moriría en

17 Ibn Sa'd, Tabaqāt, ii. 1, p. 83.

18 Ibn Isḥāq, Sīrāt, p. 456.

19 CORRIENTE, Federico y MONFERRER, Juan Pedro (2006), Las diez mu allaqāt. Poesía y panorama de Arabia en vísperas del Islam, Hiperión, Madrid.

20 Tabarī, Ta'rīkh, viii, pp. 18-19.

21 MERNISSI, Harén, p. 185.

22 Ibn Isḥāq, Sìrāt, p. 457; Ṭabarī, Ta'rīkh, viii, p. 19. 
combate. ${ }^{23}$ Esta entrada en el espacio femenino, será interpretada posteriormente por la tradición islámica, en época 'abbāsí, como una violación de un mundo que debía estar vedado a los hombres - salvo los eunucos, los únicos capacitados para estar con ellas-. No obstante, no hay una censura de este comportamiento. Son aún las costumbres de la diāhiliyya, el tiempo de la ignorancia.

Pero hay otras tradiciones, posteriores, que le dan al episodio un aire más caballeresco, más del gusto de la corte de los 'Abbāsíes, aunque también tengan por transmisora a la propia ' $\bar{A}$ 'isha. El escenario en el que se desarrolla la acción es un jardín amurallado por el que estaba paseando la esposa del Profeta. Según cuenta ella misma, en el momento de la batalla, había salido afuera siguiendo a los hombres cuando pasó junto a ella Sa'd ibn Mu'āth, armado con la cota de malla corta, acompañado por su sobrino al-Hārith ibn Aws, que le sujetaba el escudo. ${ }^{24} \mathrm{El}$ tradicionista está dibujando un espacio que difícilmente se correspondería con el de la Medina de estos primeros años del islam, con una fortaleza a la que estaba adherido un jardín para el deleite de quienes vivían en ella. No obstante, este espacio ajardinado se presta mucho mejor para la historia que se desarrollará, que no una torre de adobe en mitad de un oasis.

En el interior de ese jardín amurallado, asistió 'A' isha a la escena principal de lo que podríamos llamar el Cantar de al-Khandaq, que tiene como protagonista a 'Umar ibn al-Khaț̣āb y a un misterioso guerrero cuyo rostro estaba cubierto por un tasbighah, la cota de malla que se acoplaba al casco y que sólo permitía ver los ojos. ${ }^{25}$ Se trataba de un armamento que habría empezado a usarse a partir de las reformas militares de Cosroes I, en la segunda mitad del siglo $\mathrm{Vl} .{ }^{26} \mathrm{Es}$ una estampa que recuerda mucho a esos guerreros persas sasánidas esculpidos en los bajorrelieves de Tagh-e-Bostan. En este caso sí podemos sostener las reticencias de H. Kennedy sobre la veracidad o no de la existencia de este tipo de caballeros armados "a la sasánida".

Podría ser una invención del tradicionista en favor de su relato. Era necesario mantener en secreto la identidad del guerrero que debe salir en defensa de la dama. Descubierta 'A' isha por 'Umar, el futuro califa la reprende por

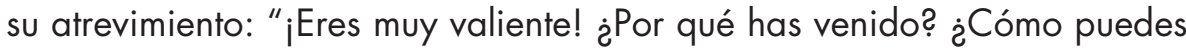

23 Ibn Isḥāq, Sīrāt, p. 457; Ṭabarī, Ta'rīkh, viii, p. 20.

24 Ṭabarī, Ta'rīkh, viii, p. 21

25 Tabarī, Ta'rīkh, viii, p. 21.

26 FARROKH, Shadows, p. 231. 
saberlo?". ${ }^{27}$ Es de sobra conocida la animadversión que lbn al-Khațāāb sentía por la joven esposa de Muhammad; la tradición siempre lo presentará como un rigorista al que ' $\bar{A}$ ' isha deja con frecuencia en evidencia delante del resto de la Umma. En medio de este altercado es cuando se produjo la revelación de la identidad del misterioso guerrero: Talḥa ibn 'Ubayd Allāh, que reprende a 'Umar por haber hablado demasiado. ${ }^{28} \mathrm{Es}$ uno más de una larga lista de incidentes que tienen como protagonistas a Ibn al-Khațāa y las mujeres del Profeta, por la libertad de la que éstas gozaban y que ponían en peligro los equilibrios sociales, por más que en el Corán se insista en que deben estar recluidas y ser modestas. ${ }^{29}$ 'Umar tenía miedo a una rebelión por parte de las musulmanas, que quisieran imitar la conducta de las mujeres de Muhammad o de las medinesas. ${ }^{30}$

La tradición islámica ha querido que en este momento Ṭalha se enamorara de la joven esposa del Profeta. ${ }^{31}$ Pero este hombre, pariente de Abū Bakr, pasa por ser uno de los primeros en aceptar el islam y a Muhammad como el Enviado de Dios, ${ }^{32}$ lo que lo convertía en miembro de la primera aristocracia islámica propiamente dicha. No obstante el enfrentamiento Talha-'Umar no se quedará ahí: Talhạa recriminó a Abū Bakr que nombrara como sucesor a un hombre como 'Umar, famoso por su rigorismo y el miedo que inspiraba en su pueblo. ${ }^{33}$

27 Ṭabarī, Ta'rïkh, viii, p. 21

28 Ṭabarī, Ta'rïkh, viii, p. 21.

29 GEISSINGER, "'A'isha", p. 39

30 SPELlBERG, Denise A. (1991), "Political Action and Public Example: 'A'isha and the Battle of Camel", en KEDDIE, Nikki E. y BARON, Beth (eds.), Women in Middle Eastern History. Shiffing Boundaries in Sex and Gender, Yale University Press, Londres/New Haven, pp 45-57, espec. 47; y MERNISSI, Harén, pp. 163-165.

31 ABBOTT, Nabia (1942), Aishah, the beloved of Muhammad, University of Chicago Press, Chicago, p. 58.

32 DONNER, Fred M. (2010), Muhammad and the Believers. At the Origins of Islam, Harvard University Press, Cambridge/Londres, Massachusetts/Londres, p. 42.

33 Țabarī, Ta'rikh, xi, p. 153 [BLANKINSHIP, Khalid Yahya (1993), The History of al-Tabarī. Vol. 11: The Challenge to the Empires, SUNY, Nueva York]. 


\section{LA GUERRA POR OTROS MEDIOS: EL CUERPO FEMENINO COMO ARMA Y LA PROPA- GANDA}

Fue en el mes de sha'bān del $6 \mathrm{AH}$ (ca. diciembre 627) ${ }^{34}$ cuando los musulmanes liderados por su Profeta partieron en campaña contra la tribu de los Banū al-Mușțaliq, ubicada en al-Muraysī', un oasis costero, hacia el sur, en dirección a La Meca, en las inmediaciones de Qudayd. ${ }^{35}$ Se trataba de una de esas expediciones de castigo que Muhammad lanzaba, encabezándolas él mismo, cuando, como en este caso, le llegaban noticias de que estaban conspirando en su contra. Pero quizás haya que apuntar en otra dirección: Qudayd era sede de un templo dedicado a la diosa Manāt, conectado con los qurayshíes, que obtendrían pingües beneficios de los rituales anuales que se celebraran allí. Ibn al-Kalbī (m. 819/821) sostiene que este santuario "fue levantado en la costa en las cercanías de al-Mushallal en Qudayd [...]. Todos los árabes solían venerarla y ofrecerle sacrificios". ${ }^{36}$ Era un templo que formaba parte del ḥadjij durante la diāhiliyya. ${ }^{37}$

Por tanto, no se trataría sólo de castigar a unos posibles rebeldes, sino de atacar uno de los negocios más lucrativos de quienes en esos momentos eran sus enemigos. Habría que leerla como una expedición para la obtención de botín y al mismo tiempo, calmar los ánimos entre los muhādjirūn (=emigrados) y los anșār (=ayudantes), después de los meses de reposo que habían pasado en Medina. Entra dentro de lo lógico el que se lanzaran a una expedición de este tipo después de las pérdidas, tanto humanas como materiales, que les había ocasionado el asedio y la batalla de Khandaq, unos meses antes.

¿Hubo realmente un complot orquestado por al-Ḥārith Abū Ḍirār o ésto sólo fue la excusa para caer sobre los Banū al-Mușțaliq en al-Muraysī'? Inmediatamente después de rechazar a los sitiadores en Medina, Muhammad decidió acabar con la tribu judía de los Banū Qurayẓa, a los que asedió durante veinticinco días y después exterminó porque jamás abandonarían su fe ancestral; $;{ }^{38}$ mientras hubiera un miembro de esta tribu, el Profeta nun-

34 Otras tradiciones lo adelantan un año, a sha'bān del 5 AH (ca. diciembre 626), Ibn Sa'd, Tabaqāt, ii. 1, p. 77.

35 Ibn Isḥāq, Sīrāt, p. 490; Tabarī, Ta'rīkh, viii, p. 51.

36 Ibn al-Kalbī, Așnām, p. 12 [FARIS, Nabih A. (1952), Hisham ibn al-Kalbi. The Book of Idols, Princeton University Press, Princeton].

37 Ibn al-Kalbī, Așnām, p. 13; CRONE, Patricia (1987), Meccan Trade and the Rise of Islam, Princeton University Press, Priceton, p. 191

38 Ibn Isḥāq, Sirrāt, p. 461-464; Tabarī, Ta'rīkh, viii, p. 27-41. 
ca hubiera podido consolidar su posición como líder en Medina y mucho menos haber conquistado La Meca. Pero obviamente, la tradición islámica no presenta este hecho como algo nacido de la voluntad de Muhammad, en tanto que líder político, sino que éste se mueve obedeciendo las órdenes de Gabriel, es decir, de Dios. ${ }^{39}$ Un comportamiento en línea con la teología del hērem judía, el exterminio de los enemigos de la fe. La expedición contra los Banū Lị̣yān es una continuación de la venganza que Muhammad quiso cobrarse sobre sus enemigos; eran la siguiente pieza que debía caer después de los Banū Qurayzạ. ${ }^{40}$ Pero la expedición contra los Dhū Qarad tuvo el carácter típico de las guerras tribales: era la respuesta del Profeta contra aquéllos que habían atacado sus rebaños de camellos. ${ }^{41}$

El resultado de la expedición contra los Muștaliq habla por sí solo: "mataron a muchos de ellos y entregaron a sus mujeres, hijos y propiedades como botín". ${ }^{42}$ La tradición que recogió al-Tabarī sobre el raid añade que este botín le fue entregado a Muhammad por Dios. ${ }^{43}$ Era el Profeta, como máxima autoridad de esa tribu que era la Umma, quien debía hacer los lotes a repartir entre quienes participaron en la expedición y lo hará con una cierta ecuanimidad. Eso es al menos lo que permite colegir una tradición transmitida por ' $\bar{A}$ ' isha al respecto del matrimonio de su esposo con Diūwayriyya al-Hārith Abū Dirār, recogida por lbn Sa d: "y tomó [Muhammad] el khums (=quinto) de ello y entonces lo dividió entre el pueblo. Dio a los jinetes dos partes y a los infantes dos partes", ${ }^{44}$ bien fueran esclavos, esclavas y otro tipo de bienes. En la parte de las Tabaqāt que dedica a la vida del Profeta, indica que un camello equivalía a diez cabras. ${ }^{45}$ Diūwayriyya entraba también entre lo repartido. Viuda de veinte años de Musafī' ibn Safwān, muerto en la batalla, ${ }^{46}$ la propia 'A' isha reconoce la animadversión que sintió por ella nada más verla; celos por cómo miraban los demás hombres a Diūwayriyya cautivados por su belleza. ${ }^{47}$

39 Ibn Sa'd, Tabaqāt, ii. 1, pp. 91-93.

40 Ibn Isḥāq, Sīrāt, p. 485-486; Ibn Sa d, Tabaqāt, ii. 1, pp. 97-99; Tabarī, Ta'rīkh, viii, p. 42-43.

41 Ibn Isḥāq, Sīrāt, p. 486-490; Tabarī, Ta'rīkh, viii, p. 43-51.

42 Ibn Isḥāq, Sìrāt, p. 490.

43 Tabarī, Ta'rīkh, viii, p. 51.

44 Ibn Sa'd, Tabaqāt, viii, p. 83.

45 Ibn Sa'd, Tabaqāt, ii. 1, p. 78.

46 Ibn Sa'd, Tabaqāt, viii, p. 83. Otras tradiciones no hacen mención a que antes hubiera estado casada: Ibn Isḥāq, Sīrāt, p. 493; Ṭabarī, Ta’rīkh, viii, p. 57.

47 Ibn Isḥāq, Sīrāt, p. 493; Ibn Sa d, Țabaqāt, viii, p. 83; Tabarī, Ta'rīkh, viii, p. 57. 
Tal vez haya que reconsiderar todo lo relacionado con la hija de Ḥārith Abū Dirār para darle una nueva interpretación a la acusación de adulterio contra ' $\bar{A}$ ' isha. Especialmente, en lo concerniente al comportamiento de Muhammad con el reparto del botín. He mencionado cómo la tradición islámica hace hincapié en la equidad con la que se procedió; una cuestión que debería servir para acallar cualquier crítica por cómo se condujo. Y aquí volvemos a la figura de Diūwayriyya. De acuerdo con todas las fuentes, la hija del líder de los Banū al-Mușțaliq había sido entregada como parte del lote que correspondía a Thābit ibn Qays ibn al-Shammās o a un primo suyo, ni la propia Diūwayriyya parecía estar muy segura de quién era su dueño. Pero lo importante es que ella acude a Muḥammad para que la liberase en atención a su estatus, en tanto que hija de un jefe tribal. Lejos de hacer valer los derechos de Thābit o su primo, el Profeta decidió quedarse con la mujer. Naturalmente, la liberó como paso previo a su boda con ella, que entró a formar parte de su harén. ${ }^{48}$ Pero el asunto no quedó ahí, y - siempre de acuerdo con la tradición islámica- el Profeta concedió la libertad a los prisioneros que ya habían sido repartidos entre los participantes de la expedición. ${ }^{49}$

Por más que se trate de presentarlo como un gesto de generosidad, lo que hizo Muhammad con Diūwayriyya fue una arbitrariedad, al quedarse con el botín de uno de sus hombres. Es lógico que levantara algunas ampollas entre los afectados y que éstos buscaran un modo de resarcirse. A ello habría que sumar la disputa por un manantial entre los muhādjirūn y los anșār, que se saldó con la derrota de estos últimos. ${ }^{50}$

Los responsables de la acusación de adulterio contra ' $\bar{A}$ ' isha fueron algunos miembros de la tribu de al-Khazradj, parte importante de los anșār. ${ }^{51}$ Ésta fue la otra guerra en la que 'A' isha tuvo que combatir y ver cómo antiguos aliados se mostraban tibios y dejaban de apoyarla. La acusación se perfila como una venganza política de los ayudantes contra los emigrados, celosos de los privilegios que éstos han ido acumulando, a costa de haber arrinconado a la oligarquía tradicional medinesa. ${ }^{52}$ Pero también se trató de un modo de expresar cierta oposición a las maneras que estaba adoptando el gobierno de Muhammad en Medina. Condenar a la hija de

48 Ibn Isḥāq, Sīrāt, p. 493; Ibn Sa 'd, Ṭabaqāt, ii. 1, pp. 78-79, VIII, p. 83; Ṭabarī, Ta'rïkh, viii, p. 57.

49 Ibn Sa'd, Tabaqāt, ii. 1, p. 79.

50 Ibn Sa'd, Tabaqāt, ii. 1, p. 79.

51 Ibn Isḥāq, Sïrāt, p. 495; Ṭabarī, Ta'rīkh, VIII, p. 61.

52 MONTGOMERY WATT, William (1956), Muhammad at Medina, Clarendon Press, Oxford. p. 186. 
Abū Bakr por adulterio hubiera comprometido seriamente su posición en la Umma; dejaría de ser uno de los hombres clave de la hierocracia construida por el Profeta en Medina y su puesto debería ser ocupado por otros, por qué no de las tribus de al-Khazradj.

De lo que no cabe duda alguna es de que 'A 'isha fue en todo momento un arma en manos de unos y otros por el poder. Quizás se pueda incluso plantear como hipótesis, como ya hizo Nabia Abbott, el que los munāfiqūn, miembros de los anșār buscaran, deslegitimando a Muhammad a través de la más joven de sus esposas, hacerse con el poder. ${ }^{53}$ Aunque creo que va más allá de las ambiciones personales de un personaje como 'Abd Allāh ibn Ubayy.

Habría que introducir algunos matices. La traducción más habitual que se ha dado para el término munāfiqūn es el de "hipócritas", pero el origen del término árabe habría que buscarlo en el etíope y el griego, ambos con el significado de "hereje", como aquel que se ha apartado del camino recto. ${ }^{54}$ 'Abd Allāh ibn Ubayy no era un mero arribista, sino que ya gozaba de una situación de preeminencia en la Medina previa a la llegada de Muhammad y los muhādjirūn. Según el relato de Ibn Ishāâ, fue a él a quien le consultan sobre la conveniencia o no de aceptar a los refugiados de La Meca, como el sheikh, el hombre fuerte de la ciudad, apoyado por un homólogo de los 'Aws, como propone P. Crone..$^{55}$ Según una tradición de la que se hace eco al-Balādhurī, ambas tribus estarían emparentadas, por vía materna, con los Banū Ghassān, ${ }^{56}$ lo que abre la posibilidad de que fueran cristianos monofisitas o al menos mostraran ciertas inclinaciones por esta Iglesia.

La irrupción en la escena medinesa de los musulmanes, dejó en suspenso la "entronización" de Ibn Ubayy como rey, como malik. De acuerdo con el relato de la Sirrāt Rasūl Allāh, al parecer todo estaba preparado para su coronación: "La gente de 'Abd Allāh ibn Ubayy había hecho una especie de diadema enjoyada para coronarlo y hacerlo su rey cuando Dios les envió a Su Mensajero" ${ }^{57}$ El hecho de que su pueblo lo abandonara para aceptar el islam y que por tanto su ascenso a la realeza quedara truncado, sería

\section{ABBOTT, Aishah, p. 29.}

54 JEFFERY, Arthur (2007), The Foreing Vocabulary of the Qur'ān. With a foreword by Gerhard Böwering and Jane Dammen McAulliffe, E. J. Brill, Leiden/Boston, [1 ${ }^{a}$ ed. 1932], p. 272.

55 Ibn Isḥāq, Sìrāt, pp. 205-206; CRONE, Meccan Trade, p. 217.

56 Balādhurī, Futūh, p. 33 [Hitti, Philip Khuri (trad.) (1916), The origins of the Islamic State, al-Baladhuri (K. Futūḥ al-Buldān), Columbia University Press, Nueva York].

57 Ibn Isḥāq, Sīrāt, p. 278. 
uno de los puntos de fricción con los recién llegados, a pesar de que, según reconoce el primer biógrafo del Profeta, Ibn Ubayy también aceptara la nueva religión, aunque por motivos de pragmatismo político. ${ }^{58} \mathrm{El}$ hecho de que se use el término munāfiqūn y no el de kuffār (sing. kāfir) indicaría que no se trata de una diferencia religiosa, de la no aceptación del islam, sino de oponerse a Muhammad como líder político. De la raíz k-f-r, significó en un primer momento "cubrir" u "ocultar", pero por influencia del arameo y el hebreo, es decir, del sistema de valores del judaísmo, la palabra se cargó de un contenido religioso, moral, identificando a los incrédulos, a los que niegan la existencia de Dios. ${ }^{59}$ No era el caso de los medineses partidarios de Ibn Ubayy, que tal vez compartieran buena parte de los postulados religiosos del Profeta, pero no su afán por acabar con la independencia de Medina. A fin de cuentas, se trataría de conservar los privilegios de la antigua aristocracia por medio de la deposición de Muhammad, atacando su moralidad a través de la de 'A' isha.

Todo este caso de la acusación de adulterio, lo que la tradición islámica llama el 'ifk, "el asunto de la mentira", tiene ciertos toques novelescos por el modo en el que se produjo y se desarrolló. Durante el regreso a Medina tras la expedición contra los Banū al-Mușțaliq, 'A' isha marchaba sobre un palanquín a lomos de un camello y quedó rezagada. Según cuenta ella misma - de acuerdo con las tradiciones recogidas que la tienen como la autoridad principal del isnād (=cadena de transmisión)-, cuando las mujeres del Profeta acompañaban al ejército musulmán, estaban sujetas a las mismas privaciones, 60 pero en torno a ella iba una serie de hombres encargados de ensillar el camello y guiarlo durante la marcha, agarrado por las bridas. No obstante, lo más interesante y lo que dará en parte pie a todo el affaire, es que ' $\bar{A}$ 'isha viajaba completamente oculta, protegida por el hidjāb que envolvía el palanquín. Por eso, los hombres a su servicio creyeron que estaba dentro cuando lo colocaron de nuevo sobre el lomo del animal para reanudar el camino a Medina. Pero la chica no estaba. De acuerdo con su propio testimonio, había tenido que ir a aliviarse cuando se dio la orden de proseguir la marcha. Y aquí vuelve a ponerse de manifiesto la nueva moral que se había impuesto en lo concerniente al comportamiento de las mujeres en la esfera pública. Obediente a las directrices

58 Ibn Isḥāq, Sīrāt, p. 279.

59 MONFERRER, Juan Pedro (2006), "«¿̨ué les queda a las putas para jactarse?». Una invectiva paleoislámica de subtemática proto-martirial", Al-Andalus Magreb:Estudios árabes e islámicos, vol. 13, pp. 163-181, espec. 171; y JEFFERY, Foreing Vocabulary, p. 250.

60 Ibn Isḥāq, Sìrāt, p. 494; Tabarī, Ta'rīkh, viii, p. 58. 
recientemente impuestas por Muḥammad, 'A' isha improvisó un hidjāb con su propia ropa para resguardarse de las miradas de los musulmanes que acudieran en su búsqueda. ${ }^{61}$

Ante todo, había que preservar la integridad moral de la nueva mujer musulmana. Sin embargo, esta actitud no evitó que se acusara a 'A' isha de adulterio. Hay dos episodios que jugaron en su contra. En primer lugar, la desaparición del collar de cuentas que su marido le trajera de Zafār y según ella misma confiesa, perdió sin darse cuenta la mañana misma en que quedó rezagada. ${ }^{62}$ Su ausencia sería una de las pruebas esgrimidas por los al-Khazradi para armar todo el revuelo. No obstante sería el comportamiento poco acorde con esa misma nueva moral que demostró Șafwān ibn al-Mu atțal al-Sulamī, de quien 'A' isha cuenta que también se había quedado rezagado del resto del ejército y que pasó por delante de donde ella estaba y levantó el hidjāb con el que se cubría. Reconociéndola como la esposa del Profeta, le preguntó por qué estaba allí pero ella no le respondió. Sería Șafwān quien la condujera de regreso a Medina, pero marchando detrás del camello, ${ }^{63}$ quizás como un gesto de respeto tanto por la joven a la que acompañaba como por el hombre con el que estaba casada.

Los días que siguieron a su regreso fueron extraños para ella. Es llamativa la queja que expresa: "Cuando estaba enferma, él [Muhammad] solía mostrarme su compasión y bondad, pero en esta enfermedad no hizo nada y lo eché de menos". ${ }^{64}$ Muestra la soledad que sintió y lo delicado de la situación en que se encontraba, no sólo ella, sino su propia familia, su padre y su esposo. Pero sobre todo es una prueba de que se trataba de una adolescente de trece años envuelta en los juegos de la política tribal. 'A' isha no sabe nada de qué está pasando hasta que no se lo dice una de las instigadoras del bulo: Misțaḥ bint Djaḥsh, la hermana de Zaynab, y esposa del Profeta, pertenecientes al clan de 'Awf $f^{65}$ - una división de los al-Khazradi-. De hecho, ella misma estaba emparentada con Misțaḥ: su madre era prima de Abū Bakr, ${ }^{66}$ dándole al asunto del 'ifk un cierto aroma a rencilla familiar. Sin embargo, quizás lo más destacado sea la actitud

61 Ibn Isḥāq, Sirrāt, p. 494; Tabarī, Ta'rīkh, viii, p. 59.

62 Ibn Isḥāq, Sïrāt, p. 494; Ṭabarī, Ta'rīkh, viii, p. 59.

63 Ibn Isḥāq, Sīrāt, p. 494; Ṭabarī, Ta'rīkh, viii, p. 59.

64 lbn Isḥāq, Sīrāt, p. 495.

65 bn Isḥāq, Sīrāt, p. 495.

66 Ibn Isḥāq, Sìrāt, p. 495; Ṭabarī, Ta'rīkh, viii, p. 60. 
que demostraron los hombres en esa reunión convocada por Muhammad para tratar de esclarecer la situación y dilucidar qué hacer con 'A 'isha en caso de ser hallada culpable.

Que era una cuestión tribal queda fuera de toda duda. Proteger el honor de la joven esposa del Profeta equivalía para muchos a proteger el suyo propio. Pero en este caso, va mucho más allá, ya que se trataría de hacer valer la importancia de un grupo extraño, los muhādjirūn, incardinados en un cuerpo extraño, como era la sociedad de Medina. La acusación de adulterio lanzada contra ' $\bar{A}$ 'isha podría haberse convertido perfectamente en un casus belli que hubiera dinamitado la unión con los anșār, envueltos ambos grupos en una guerra civil. Es al menos lo que se desprende de las palabras de uno de los convocados a esa reunión: "Si son [los difamadores] de los 'Aws, nos deshacemos de ellos; si son de los al-Khazradj, danos tus órdenes porque deberían tener las cabezas cortadas". ${ }^{67}$ Deja poco lugar a dudas acerca de la animadversión que sentían por ambas tribus, e iría más allá de un conflicto con los munāfiqūn. No obstante, en esa reunión había otros que estaban dispuestos a defender los derechos de los anșār, evitando el derramamiento de sangre quizás por sus propios intereses, marcados por su posición dentro de la Umma y sus relaciones con los medineses. La prudencia de algunos hombres "piadosos" habría que leerla como el reconocimiento de la debilidad de los musulmanes. No olvidaban que eran un grupo encastrado en otro mayor y que no eran sino huéspedes. Empezar una guerra contra los al-Khazradj hubiera supuesto la aniquilación.

No obstante, sobre lo que me interesa llamar la atención es acerca de la postura adoptada por 'Alī ibn Abī Ṭālib en el transcurso de la reunión/juicio que se estaba siguiendo. $Y$ me resulta importante porque en buena medida marcó lo que sucederá casi treinta años más tarde. El juicio del primo del Profeta muestra a 'A' isha como una pieza reemplazable: "Las mujeres son abundantes y fácilmente puedes cambiar una por otra". ${ }^{68}$ Una posición muy inestable para la que sería conocida como umm al-mu'minin (=madre de los creyentes), como todas las esposas de Muhammad, además por revelación divina: "Las esposas de aquél [el Profeta], son las madres de éstos [los musulmanes]". ${ }^{69}$ Ese modo de no implicarse en su defensa, máxime cuando pertenecían a la misma familia, tuvo que ser un golpe para 'A' isha, quien vio cómo uno de los principales hombres de la comunidad le daba la espalda.

67 Ibn Isḥāq, Sīrāt, p. 495.

68 Ibn Isḥāq, Sìrāt, p. 496; Ṭabarī, Ta'rïkh, viii, p. 62.

69 Corán, 33, 6. 
Fue 'Alī quien recomendó a Muhammad que interrogara a Burayra, la esclava que iba con su mujer, para conocer la verdad y cuyo testimonio resultaría definitivo para exculpar a 'A' isha. La única falta de la que podía acusar a su señora era que no vigilaba la masa, que se quedaba dormida y la oveja se la comía. ${ }^{70}$ Una nota de color costumbrista que viene a relajar la tensión existente y a dar un argumento para exonerar a la joven de toda culpa. Es una escena que gira en torno a la cotidianidad de las mujeres árabes - en este caso da igual que sean o no musulmanas-, cuyo espacio y funciones es el doméstico y ligado a la reproducción y sostenimiento del grupo. Lo privado-femenino versus lo público-masculino. Toda aquella mujer que se atrevía a penetrar en la esfera pública era considerada una prostituta, a la que los hombres cuestionaban su integridad y quedaba a merced de cualquier abuso. ${ }^{71}$

Antes mencionaba el uso de la poesía como arma política. En el caso de la acusación de adulterio contra 'Ā'isha, además se usó como arma de guerra entre los dos bandos enfrentados. Tuvo una participación destacada quien sería uno de los principales poetas del período paleo-islámico, primero como opositor y después, a consecuencia de este episodio, como firme partidario de Muhammad: Ḥassān ibn Thābit, miembro de los al-Khazradj. Él fue uno de los más implicados en la campaña de desprestigio emprendida contra los musulmanes a través de la figura de la más joven de las esposas de su profeta-guerrero y como tal merecedor del castigo que se le impuso, los ochenta latigazos estipulados en el Corán contra aquéllos que levantaban falsas acusaciones. ${ }^{72}$ Es un personaje que ejerció como nexo de unión entre los árabes iranizados de los Banū Lakhm y la península arábiga, ${ }^{73}$ introduciendo muchos de los usos y costumbres cortesanos en La Meca y Medina, incidiendo en una imagen mucho más "civilizada" de la Arabia pre-islámica que la que se ha venido dando.

Los versos que recoge Ibn Isḥāq prueban la animadversión de Ḥassān ibn Thābit contra los musulmanes, a los que llamaba "inmigrantes vagabundos" y acusaba de violar las leyes vigentes: no pagaban por la sangre derramada. ${ }^{74}$ Por desgracia, no se han conservado ninguna de las invec-

70 Ibn Isḥāq, Sìrāt, p. 496; Ṭabarī, Ta'rīkh, viii, p. 62.

71 BARLAS, "Believing women", p. 56.

72 Ibn Isḥāq, Sīrāt, p. 497; Ṭabarī, Ta'rīkh, viii, p. 63. Vid. Corán, 24, 4.

73 STETKEVYCH, Suzanne Pinckney (2002), The Poetics of Islamic Legitimacy. Mith, Gender and Ceremony in the Classical Arabic Ode, Indiana University Press, Bloomington/Indianapolis, pp. 44-47.

74 Ibn Isḥāq, Sīrāt, p. 498. 
tivas que lanzara contra ' $\bar{A}$ 'isha. Con todas las reservas, no sería muy descabellado que estuvieran en línea con la que compuso la musulmana Hind bint Uthāthā contra la mecana Hind bint 'Utba, en la que la acusa de haber cometido adulterio - ella también - con Waḥshī, el esclavo negro:

entregaste a Waḥshī lo que [tu] pecho sentía.

Waḥshī ha rasgado el velo del cortinaje, después de ella, ¿̇qué les queda a las putas para jactarse? ${ }^{75}$

Esta hipótesis vendría probada por los versos que compuso después de que se ejecutara la sentencia:

Casta, manteniéndose en su casa, por encima de toda sospecha, nunca pienso en vilipendiar a mujeres inocentes; una mujer noble del clan de Lu'ayy ibn Ghālib, buscadores de honor cuya gloria nunca se desvanece. ${ }^{76}$

Cualquier insulto contra la familia y el clan quedaba así reparado, aludiendo a la honestidad de sus mujeres e incidiendo en algo que ya he mencionado: el espacio doméstico, privado, como el único reservado para ellas. Era en él donde podían sentirse a salvo de cualquier peligro; pero también los hombres, que no se veían interpelados por las mujeres en la esfera pública. El del hogar es asimismo un espacio donde ellos pueden controlar más fácilmente la sexualidad femenina.

El episodio de la exoneración de 'A' isha y el castigo de los maledicentes juega con esos aspectos "caballerescos" que la cultura de la aristocracia árabe pre y paleo-islámica habrían tomado de los persas sasánidas. En este caso, el protagonista es alguien a quien ya se ha mencionado: Șafwān ibn al-Mu aț̣al. Él había dado pie, con su actuación, a que comenzaran los ataques contra la mujer de Muhammad y la tradición islámica lo presenta como el responsable de prender a Ḥassān ibn Thābit para llevarlo al suplicio. ${ }^{77}$ Era el modo de redimir su comportamiento poco respetuoso. No obstante, es igualmente ilustrativo de la tensión existente entre muhādjirūn y

75 MONFERRER, "«¿Qué les queda...?"», pp. 177-181.

76 Ibn Isḥāq, Sīrāt, p. 499.

77 Ibn Isḥāq, Sirrāt, p. 498; Tabarī, Ta'rīkh, viii, pp. 64-65. 
anșār el hecho de que Șafwān acudiera a arrestar a Ḥassān con la espada en la mano.

Muy posiblemente, fueran conscientes de que las penas impuestas desatarían represalias contra los musulmanes. Porque no sólo fue castigado el poeta, sino también dos mujeres, la ya mencionada Misțah y Ḥamna. ${ }^{78}$ Vuelvo a plantear la hipótesis de que ellas hubieran compuesto algunos versos satíricos acerca de la honestidad de 'A' isha y no sólo haberse limitado a propagar rumores por los mentideros de Medina. Pero el hecho de que el verdadero artífice e instigador de todo, Ibn Ubayy, no hubiera sido castigado pone de manifiesto que, a pesar de que Muhammad y los muhādjirūn tuvieran el monopolio de la violencia y el poder en la ciudad, la aristocracia tradicional y sus redes clientelares seguían siendo un elemento a tener en cuenta, sin los cuales Medina difícilmente podría ser gobernada.

\section{Viuda ¿SEÑora de La GUerRa?}

Cuando murió Muhammad, 'A' isha tenía dieciocho años, ${ }^{79}$ marcando un punto de inflexión en su propia vida. Su estatus como viuda, la situaba en un plano similar al de Khadīdja. Haber sido la esposa del Profeta e hija de un califa, le daba una consideración especial en la sociedad islámica. Ella, al igual que el resto de las viudas de Muhammad tenían prohibido volver a casarse. ${ }^{80}$ La tradición islámica alude a que nadie pudo acceder a la herencia dejada por el Profeta, lo que no quiere decir que ella quedara en la indigencia. Cuando cayó enfermo su padre, éste hizo a 'A' 'isha depositaria de pequeños fondos públicos y propiedades, convirtiéndola en la depositaria del legado de sus hermanos y hermanas. ${ }^{81} \mathrm{~A}$ esto habría que añadir la parte que le correspondía de las riquezas que afluían al Hiidjāz procedentes de las provincias conquistadas durante el califato de 'Umar ibn al-Khațāâ. Ibn Sa'd cuenta, por ejemplo, cómo el califa dio a las viudas de Muhammad diez mil dirhams y añadió dos mil más a la parte que le correspondía a 'A' isha por ser la esposa favorita. ${ }^{82}$

78 Ibn Isḥāq, Sīrāt, p. 497; Tabarī, Ta'rīkh, viii, pp. 63.

79 Ibn Sa'd, Tabaqāt, viii, p. 44.

80 AHMED, Leila (1992), Women and Gender in Islam. Historical Roots of a Modern Debate, Yale University Press, New Haven/Londres, pp. 49 y 74.

81 ABBOTT, Aishah, p. 85; y AHMED, Women, p. 74.

82 Ibn Sa'd, Ṭabaqāt, viii, p. 48; Ṭabarī, Ta'rīkh, xii, p. 202 [FRIEDMAN, Yohanan (1992), The History of al-Tabarī. Vol 12: The Battle of al-Qãdisiyyah and the Conquest of Syria and Palestine, SUNY, Nueva York]. 
Pero no es la única mención que hace este tradicionista a la riqueza que pudo haber amasado esta mujer a lo largo de los años. Su patrimonio procedía de los rendimientos de las herencias recibidas, ${ }^{83}$ aunque lejos de ser una rentista como la presenta la tradición islámica, no se debe descartar que ella misma se implicara, como Khadīdja, en la gestión de sus bienes. Es posible que una parte de esos fondos que le legó su padre estuvieran relacionados con la explotación de las minas de oro de la península arábiga, a los que habría que sumar los beneficios obtenidos por el comercio caravanero con Siria ${ }^{84}$ ¿̇Habría cambiado ella también el comercio por el pillaje? Quizás así se expliquen los cien mil dirhams que lbn al-Zubayr le hizo llegar y 'A' isha, según la tradición, hizo repartir entre el pueblo. ${ }^{85}$ Hace también Ibn Sa'd alusión a setenta mil dirhams que donó en calidad de șadaqa (=limosna), ${ }^{86}$ y lo determinante no es sólo la cantidad sino el objetivo de ese dinero. Se podría aventurar la idea de que pudiera servir para mantener su propia red clientelar que ' $\bar{A}$ ' isha se encargaría de movilizar cuando llegara el momento.

He planteado la hipótesis de que ' $\bar{A}$ ' isha se hubiera beneficiado de los réditos de la conquista, a través del botín traído a Medina por hombres a su servicio. Sin embargo, podría plantearse el que se implicara personalmente; que estuviera in situ en algunas campañas y más en concreto, en las que condujeron a la conquista de la Persia sasánida. No hay ninguna fuente que permita establecer su presencia en la batalla de al-Qādisiyya (636); ${ }^{87}$ no se ha conservado ningún relato que diga que efectivamente estuvo al lado de los árabes que derrotaron a Rustam. Pero quizás se pueda sostener sobre la base de los isnāds que cita al-Tabarī para este acontecimiento y que la tienen a ella como la principal autoridad de lo que cuenta. ${ }^{88}$ Esto nos permitiría aventurar que tal vez 'A' isha pudo ser testigo directo de la batalla. Quizás la viera desde el palanquín de su camello, oculta por el

83 Ibn Sa'd, Țabaqāt, viii, p. 47; AHMED, Women, p. 80.

84 CRONE, Meccan Trade, pp. 94 y 116.

85 Ibn Sa'd, Tabaqāt, viii, p. 47.

86 Ibn Sa'd, Tabaqāt, viii, p. 47.

87 McGRAW DONNER, Fred (1981), The Early Islamic Conquest, Princeton University Press, Princeton, pp. 203-210; y POURSHARIATI, Parvaneh (2008), Decline and Fall of the Sasanian Empire. The Sasanian-Parthian Confederacy and the Arab Conquest of Iran, Tauris, Londres/ Nueva York, pp. 232-236.

88 Ṭabarī, Ta'rīkh, xii, p. 46 y xiii, p. 10 [JUYNBOLL, Gautier H. A. (1989), The History of al-Tabarī. Vol 13: The Conquest of Iraq, Southwestern Persian and Egypt, SUNY, Nueva York]. 
hidjāb, a salvo de miradas indiscretas. Sabemos por Mas 'ūdī y otros tradicionistas, que Țalḥa ibn 'Ubayd Allāh y Zubayr ibn al-'Awwām estaban con el ejército que combatió en la batalla del Puente $(634)^{89}$ y no sería descartable que la viuda de Muhammad acompañara a quienes eran sus aliados más cercanos, en especial a Țalha. De hecho, sabemos de la presencia de un número considerable de mujeres de las tribus árabes que acabaron por casarse con los veteranos asentados en la zona tras la batalla, aunque pertenecientes a otros clanes. ${ }^{90}$

Entre finales del año 23 y comienzos del $24 \mathrm{AH}$ (ca. 644), en la Umma se produjo un cambio de tendencia. El asesinato del califa 'Umar ibn alKhatțāâ ${ }^{91}$ iba a marcar el fin de un califato cuya sucesión se había mantenido fuera de las lógicas tribales, por más que 'Umar hubiera sido suegro de Muhammad. Se pusieron de manifiesto, una vez más, las tensiones existentes entre los diferentes grupos que conformaban el primer Estado islámico, acrecentadas por el éxito fulgurante de las campañas de conquista. Pero nos equivocaríamos si pensáramos que las luchas por el poder, por establecer quién ostentaría el título de califa, era algo que ocupaba a toda la comunidad. Antes bien, ésto se consideraba un asunto local, una disputa interna que afectaba a las elites de Medina especialmente. ${ }^{92}$

La elección del sucesor de 'Umar no competía a toda la Umma, sino que debía decidirse entre un grupo aristocrático. Es lo que en la tradición islámica ha pasado con el nombre de shūrā, un collegium formado en este caso por seis hombres procedentes de la nueva elite. Entre ellos estaban ' $U$ thmān ibn 'Affān y 'Alī ibn Abī Ṭālib, pero también Ṭalḥa ibn 'Ubayd Allāh y Zubayr ibn al-'Awwām, junto con otros dos miembros más de esa casta arabo-musulmana que se había hecho con el poder en el Ḥidjāz. ${ }^{93}$ Sin embargo, esta shūrā no podría adoptar ninguna resolución sin que antes ' $\bar{A}$ 'isha

89 Ṭabarī, Ta'rīkh, xii, pp. 5-6; Mas'ūdī, Murūdj, iv, § LXXVI, p. 201 [BARBIER DE MEYNAR, Charles y DE COURTEILLE, Pavet (1965), Les prairies d'or. Revisada y corregida por Charles Pellat. 4 vols., Societé Asiatique, París]. Sobre la batalla, vid. McGRAW DONNER, Early Islamic, pp. 197-200; y POURSHARIATI, Decline and Fall, pp. 214-219.

90 MORONY, Michael (1984), Iraq after de Muslim Conquest, Princeton University Press, Princeton, p. 237.

91 Mas 'ūdī, Murūdj, iv, § LXXVI, p. 226-228; Tabarī, Ta'rïkh, xiv, pp. 89-93 SMITH, Gerald Rex. (1994), The History of al-Tabarī. Vol 14: The Conquest of Iran, SUNY, Nueva York].

92 CAETANI, Leone (1914), Annali dell'Islam, vol. 7, Ulrico Hoepli, Milán, § 2.

93 Ṭabarī, Ta'rïkh, xiv, pp. 145-146. 
diera su visto bueno. ${ }^{94} \dot{2}$ Esta consideración se debía sólo a que había sido la esposa favorita de Muhammad? Tal vez haya que pensar que respondía a un reconocimiento implícito a su papel en el desarrollo del Estado paleo-islámico. Hemos visto cómo había amasado una considerable fortuna y que con toda probabilidad se viera envuelta en parte de la conquista de la Persia sasánida. 'A' isha se perfila como un elemento político a tener en cuenta en lo que a la estabilidad del califato se refiere. Obviamente, no la iban a sentar en pie de igualdad con el resto de los prohombres musulmanes, pero su aquiescencia o negativa suponía que sus clientes se movieran en un sentido u otro. Jugando, eso sí, en un campo eminentemente local, por más que la tradición islámica posterior le dé una dimensión panárabe. Hacía valer su condición de umm al-mu'mininn, de madre de los creyentes. Este título no sería algo meramente simbólico..$^{95} \mathrm{He}$ aludido antes a que en el Corán se les daba este epíteto a todas las esposas de Muhammad, pero no es menos cierto que en otra tradición, ésta recogida por Ibn Sa'd y atribuida a Ibn 'Abbās, se le da a ella este título en exclusiva. ${ }^{96}$ En un período en el que religión y política se funden y confunden, el título tendría un aspecto más práctico. Hay que recordar que, en estos momentos, no se usaba el término califa (ár. khalîfa) para referirse al máximo dirigente islámico, sino el de amīr al-mu'minīn (=caudillo de los creyentes), lo que nos llevaría, como hipótesis, a establecer una cierta concordancia entre ambos. Obviamente, no pretendo equipararlos, pero sí señalar que entrarían dentro de una misma lógica.

La autoridad de 'A' isha como umm al-mu'minin vendría marcada por un aspecto que le otorgan las tradiciones referidas a ella, la de ejercer como intermediaria entre el pueblo, los creyentes, y sus dirigentes; una autoridad de tipo no menos carismática que la ostentada por los rashidūn. Por tanto, sería este estatus politico-religioso lo que le llevaría a intervenir en la designación de los califas o lo que le legitimaría para ponerse al frente de un ejército, bien fuera durante la conquista de Persia o en la guerra civil para destronar a 'Alī. Es muy llamativo que, a pesar de ostentar este título, ella jamás fuera madre y no por ello viera menguada su influencia. ${ }^{97}$

La shūrā, el collegium elector, se había decantado finalmente por el más débil de los candidatos, por 'Uthmān ibn 'Affān; aquél que, en palabras de

94 Tabarī, Ta'rïkh, xiv, p. 145.

95 SPELLBERG, "Political Action", p. 52.

96 Ibn Sa'd, Tabaqāt, viii, p. 53.

97 BARLAS, "Believing women", p. 179. 
Mas 'ūdī, inauguró un reinado que no tenía nada que ver con la austeridad y rigorismo del anterior. ${ }^{98}$ Los hombres fuertes de Medina, como Ṭalha o el propio 'Alī, estarían esperando su oportunidad para suceder al califa en cuanto éste cayera. La "mujer fuerte", 'A' isha, en un primer momento tampoco tuvo inconveniente en que el califato recayera en él. A pesar de esto, el nuevo califa adoptó medidas en su contra, como cabeza visible de la nueva casta islámica, reduciéndole la pensión que percibía hasta situarla al mismo nivel que el resto de las viudas del Profeta. ${ }^{99}$ Era una medida que contrasta con el dispendio con el que solía actuar 'Uthmān. ${ }^{100} \mathrm{Tal}$ vez haya que verlo como un ataque directo contra la que era la principal figura femenina de Medina, sacándola de la esfera pública.

'A' isha era la única de las viudas de Muhammad que tenía un papel activo. Por eso, equipararla al resto era recordarle cuál debía ser su posición en la sociedad islámica. Tal vez por esta razón, quizás no se tratase sólo de reducirle la asignación, sino que se vetara a ' $\bar{A}$ ' isha la posibilidad de seguir gestionando los bienes que su padre le había legado y que además hubiera algún tipo de confiscación. No obstante, esto sólo son especulaciones. Hipótesis a un lado, lo cierto es que socavar su poder económico equivalía a dejarla sin opciones para actuar en la esfera pública. Formaba parte de esa política puesta en marcha por el nuevo califa, tendente a favorecer a la gente de su propio clan en detrimento de quienes habían ostentado el poder dentro de la Umma. Será ahora cuando 'Á' isha intervenga de manera más clara en la política del califato. La razón que explicaría este cambio, sería que hasta el gobierno de 'Uthmān no había visto amenazado su estatus. Esta reacción entraría dentro de la lógica de quien ha logrado alcanzar y afianzar una posición social, política y económica, a fuerza de verse cuestionada por un sector de la comunidad islámica, que la puso en entredicho. Madelung sostiene que decidió socavar las bases del califato porque pensaba que 'Alī estaba descartado para suceder a 'Uthmān; que, si el primo y yerno del Profeta daba el primer paso para alzarse en armas contra el califa, ella sería la principal perjudicada. ${ }^{101}$

$Y$ en este punto cabe la duda de si 'A' isha estaba dispuesta a tomar el poder para sí misma, haciéndose nombrar califa, o si, por el contrario, cedería ese honor a quien la acompañó durante toda su trayectoria, Țalha

98 Mas'ūdī, Murūdi, iv, § LXXVII, p. 255.

99 ABBOTT, Aishah, p. 105.

100 Mas'ūdī, Murūdj, iv, § LXXVII, p.252.

101 MADELUNG, Succession, p. 107. 
ibn 'Ubayd Allāh. De hecho, no se puede descartar la primera opción. En estos años de profundas transformaciones, hubo cabida para el gobierno de mujeres, como fue el caso de Būrāndukht y su hermana Azarmīdukht, que rigieron la Persia sasánida entre 630-632, en medio de una enorme inestabilidad política, interna - guerra civil-y externa - conquista islámica-. ${ }^{102}$ Existiendo este antecedente, es plausible que ella quisiera coronarse; contaba con los apoyos necesarios para ello. La reacción de los tradicionistas musulmanes en ambos casos, el de 'A' isha y Būrāndukht, es muy similar, avisando de los peligros que entrañaba cualquier gobierno femenino, entendido como sinónimo de inestabilidad y caos. ${ }^{103}$ Para el caso persa, Abū Bakra recuerda que al saber Muhammad que en el trono de Ctesifonte se sentaba una mujer, se lamentó por la suerte de la dinastía sasánida, condenada a desaparecer. ${ }^{104}$

\section{Conclusiones}

La guerra ha sido entendida como un mundo netamente masculino del que en principio estarían excluidas las mujeres. No obstante, ellas serán testigos y víctimas del conflicto, tomando a veces un papel protagonista que ha quedado ensombrecido, visto como una transgresión del orden social vigente, en nuestro caso, en el islam. El de 'A' isha es un ejemplo paradigmático de esa voluntad de romper ciertos clichés que tienen que ver con el confinamiento de la mujer en el espacio privado del hogar y sin ninguna implicación en la vida pública.

Ya desde ese primer contacto con la violencia de una batalla, en la lejanía y a resguardo de los muros de una fortificación, quiere inmiscuirse en el devenir de los acontecimientos. En la batalla de al-Khandaq vemos cómo la guerra deja en suspenso ciertas convenciones en lo referente a la separación del espacio según los sexos. Así pues, un hombre, un guerrero que antes que nada es también hijo de su madre, irrumpe en las habitaciones de las mujeres. Bien es cierto, que ésto se produce cuando aún Muhammad no había decretado que un velo debía mantener ocultas a las mujeres. Pero también se da a la inversa: cuando 'A' isha irrumpe en una esfera propia de los varones, esa guerra de la que ella debía mantenerse alejada. Era la curiosidad lo que la llevó hasta donde estaban los guerreros árabes que regresaban y marchaban a la batalla, donde la joven esposa de un

102 CHRISTENSEN, Iran, p. 498; y POURSHARIATI, Decline and Fall, pp. 207-214.

103 SPELLBERG, "Political Action", p. 51.

104 MERNISSI, Harén, p. 61. 
profeta-guerrero podía ser testigo de las debilidades de los hombres. La reprimenda de 'Umar no tenía que ver sólo con su seguridad, sino también con el hecho de haber entrado en un mundo que no le correspondía. Era la primera bid'a que llevaba a cabo.

Lo que ve 'A' isha, según narran las tradiciones islámicas, es una guerra de corte caballeresco; la usual en un mundo regido por las costumbres militares que habían impuesto los dos grandes imperios del momento, la Persia sasánida y el Imperio romano de Oriente. Y sobre todo ésta primera, cuya influencia en la región del Hiidjāz está fuera de toda duda: al norte se hallaba la Siria-Palestina controlada por los sasánidas y al sur, el Yemen también persa. Así, entra dentro de lo esperable que los campeones musulmán y pagano parezcan más cercanos al prototipo de guerrero aristocrático sasánida que al ideal del guerrero islámico. La propia estrategia seguida por Muhammad para detener a sus enemigos, está indicando no sólo que existía una organización militar entre las confederaciones tribales árabes, sino que éstas estaban imbuidas por las modas importadas de fuera de las fronteras de la península arábiga.

Pero la guerra se libra por otros medios y tiene al cuerpo femenino como arma y al mismo tiempo como campo de batalla. Y aquí tiene un papel destacado la concepción del honor en las sociedades patriarcales, que reside en la honra de sus mujeres. El peligro que entrañaba para la oposición de una parte importante de la oligarquía de Medina enfrentarse directamente a Muhammad, hizo que atacaran a 'A' isha como el único modo de deshacerse del profeta-guerrero que estaba imponiendo un orden de cosas con el que no estaban de acuerdo. En este sentido, la poesía satírica usada como un medio de propaganda fue fundamental. No era la primera vez que se empleaban los versos compuestos por los y las poetas tribales con el fin de denigrar al rival. La acusación de adulterio contra 'A' isha nació en el contexto de una de las expediciones de castigo contra los enemigos de los musulmanes y las disensiones que pudieron surgir por el modo en que se repartió un botín, compuesto fundamentalmente por las mujeres de la tribu vencida. El "asunto de la mentira" sentó las bases de la enemistad de la esposa de Muhammad con 'Alī ibn Abī Țālib. Su posición en el juicio, favorable al divorcio, vendría marcada por el deseo de 'Alī de no enemistarse con los medineses que habían propalado el rumor. Sabía que la posición de los emigrados mecanos era precaria y una guerra civil en Medina podía acabar con la recién nacida comunidad islámica.

Sin embargo, habrá que esperar a la viudedad de 'A' isha para verla actuar de forma autónoma, como ya lo hicieran otras viudas, como Khadīdja. Las fuentes no son claras, por lo que tenemos que leer entre líneas y plantear una serie de hipótesis que deberán ser contrastadas con nuevos relatos. 
Una de ellas es su posible participación en la conquista de Persia, partiendo de las citas que los tradicionistas hacen situándola como la principal autoridad de la que beben. Esto la convertiría en una suerte de testigo presencial de los hechos y me permite especular con la posibilidad de que ' $\bar{A}$ ' $\mathrm{i}$ sha fuera una "señora de la guerra", algo nada raro en el contexto oriental del siglo VII. La guerra, los botines obtenidos, se habrían convertido en una fuente de riqueza nada desdeñable, tanto para ella como para el resto de la sociedad árabe, que vio cómo durante los años de la conquista afluían a Medina, la capital del califato paleo-islámico, grandes cantidades de oro, plata y todo tipo de productos agrícolas y manufacturados.

Muy posiblemente, ese carácter de "señora de la guerra" unido al hecho de ser la viuda de Muhammad, le confirió una autoridad especial que le permitió intervenir en la vida política durante el gobierno de los dos últimos califas rashidūn. Llegados a este punto, la incógnita es si lo hizo movida por el deseo de poder personal o por un prurito religioso al ver que se estaban alejando de los preceptos originales del islam. Por mi parte, introduzco una tercera posibilidad: que lo hiciera en defensa de los intereses del grupo al que pertenecía, el de la nueva aristocracia islámica. 